\title{
Article \\ Balancing Reproductive and Productive Responsibilities: Childcare Strategies Implemented by Migrant Mothers in the Thailand-Myanmar Border Region
}

\author{
Lisa Wight 1,2 ${ }^{(D}$, Nway Nway Oo ${ }^{3}$, Naw Pue Pue Mhote ${ }^{4}$, Supaporn Trongsakul ${ }^{5}$, Eva Purkey ${ }^{6,7}$, \\ Susan A. Bartels ${ }^{7,8}{ }^{\mathbb{D}}$, Heather M. Aldersey ${ }^{9}$ and Colleen M. Davison ${ }^{2,7, * \mathbb{D}}$
}

\section{check for} updates

Citation: Wight, L.; Oo, N.N.; Mhote N.P.P.; Trongsakul, S.; Purkey, E.; Bartels, S.A.; Aldersey, H.M.; Davison, C.M. Balancing Reproductive and Productive Responsibilities:

Childcare Strategies Implemented by Migrant Mothers in the Thailand-Myanmar Border Region. Women 2021, 1, 280-296. https:// doi.org/10.3390/women1040024

Academic Editor: Mary V. Seeman

Received: 15 October 2021

Accepted: 10 December 2021

Published: 17 December 2021

Publisher's Note: MDPI stays neutral with regard to jurisdictional claims in published maps and institutional affiliations.

Copyright: (C) 2021 by the authors. Licensee MDPI, Basel, Switzerland. This article is an open access article distributed under the terms and conditions of the Creative Commons Attribution (CC BY) license (https:// creativecommons.org/licenses/by/ $4.0 /)$.
1 Faculty of Arts and Science, Queen's University, Kingston, ON K7L 3P5, Canada; 1.wight@queensu.ca Department of Global Development Studies, Queen's University, Kingston, ON K7L 3P5, Canada Protection for Children and Women, Mae Tao Clinic, Mae Sot 63110, Thailand; Loy.Kyinno@maetaoclinic.org Health Information Systems Working Group, Mae Sot 63110, Thailand; teetarsway@gmail.com School of Health Science, Mae Fah Luang University, Chiang Rai 57100, Thailand; supaporn.tro@mfu.ac.th Department of Family Medicine, Queen's University, Kingston, ON K7L 3G2, Canada; eva.purkey@queensu.ca

7 Department of Public Health Sciences, Queen's University, Kingston, ON K7L 3L3, Canada; susan.bartels@queensu.ca

8 Department of Emergency Medicine, Queen's University, Kingston, ON K7L 3G2, Canada

9 School of Rehabilitation Therapy, Queen's University, Kingston, ON K7L 3N6, Canada; hma@queensu.ca

* Correspondence: davisonc@queensu.ca; Tel.: +1-613-533-6000 (ext. 79518)

Abstract: Background: In Myanmar, formerly known as Burma, conflicts between ethnic minorities, the government, and the military have been ongoing for decades. Enduring unrest has caused thousands to flee to the region around Mae Sot, a city on Thailand's western border. Women around the world assume a combination of reproductive and productive responsibilities, and during situations of armed conflict and displacement, conditions for women often worsen. This study investigated the parenting experiences of female migrants from Myanmar living in protracted refugee situations in Mae Sot. Methods: This research was part of a mixed-methods international comparative study on the experiences of parenting in adversity. In this analysis, 62 first-person qualitative narratives shared by migrant mothers in the Thailand-Myanmar border region were inductively analyzed using the Qualitative Analysis Guide of Leuven method. Results: The results highlight how migrant mothers undertake significant reproductive responsibilities, such as breastfeeding and child-rearing, as well as productive responsibilities, including paid labour in the agricultural, formal, and informal sectors. In order to care and provide for their families, female migrants in the Thailand-Myanmar border region utilized four childcare strategies: caring for children while working, caring for children instead of working, dispersing responsibilities amongst extended family members and children, and delegating reproductive responsibilities to formal and non-familial caretakers. Conclusions: Most mothers shared stories in which they or their immediate family members cared for their children, rather than depending on neighbours or formal childminders. Female migrants may face challenges locating desirable work that is compatible with childcare, rendering certain childcare arrangement strategies more prevalent than others. Further research could elucidate these challenges and how opportunities for gainful employment that are conducive to childcare can be generated for women living in protracted refugee situations.

Keywords: migrant women; refugee; parenting; qualitative research; maternal and child well-being

\section{Introduction \\ 1.1. Historical and Political Context in Myanmar}

Myanmar, formerly and currently known by some as Burma, is a lower-middle-income country and is one of the most diverse regions in Southeast Asia, consisting of more than 130 
ethnic groups [1]. Primarily in the eastern border region, conflicts between minority ethnic groups, the government, and the military for autonomy within the framework of a federal union have been ongoing since at least the time of independence in 1948 [2,3]. Lasting legacies of colonial rule, military coup d'états, and socialist military dictatorships have had enormous impacts on the country's current social, political, and economic conditions. Minority ethnic groups have faced forced displacement and relocation, appropriation of land, and destruction of villages in contested areas throughout the eastern border region [4]. Severe human rights abuses have also been perpetrated against ethnic minorities, resulting in intense conflicts between ethnic armed militias and the government military [5]. Despite temporary ceasefire agreements between fourteen out of sixteen main armed groups and the government, the Burmese military has not withdrawn troops from many contested ethnic states and fighting has continued [1]. Enduring unrest has caused thousands of people, members of ethnic minority groups as well as others, to flee to the region around Mae Sot, a city on Thailand's western border, as illustrated in Figure 1.

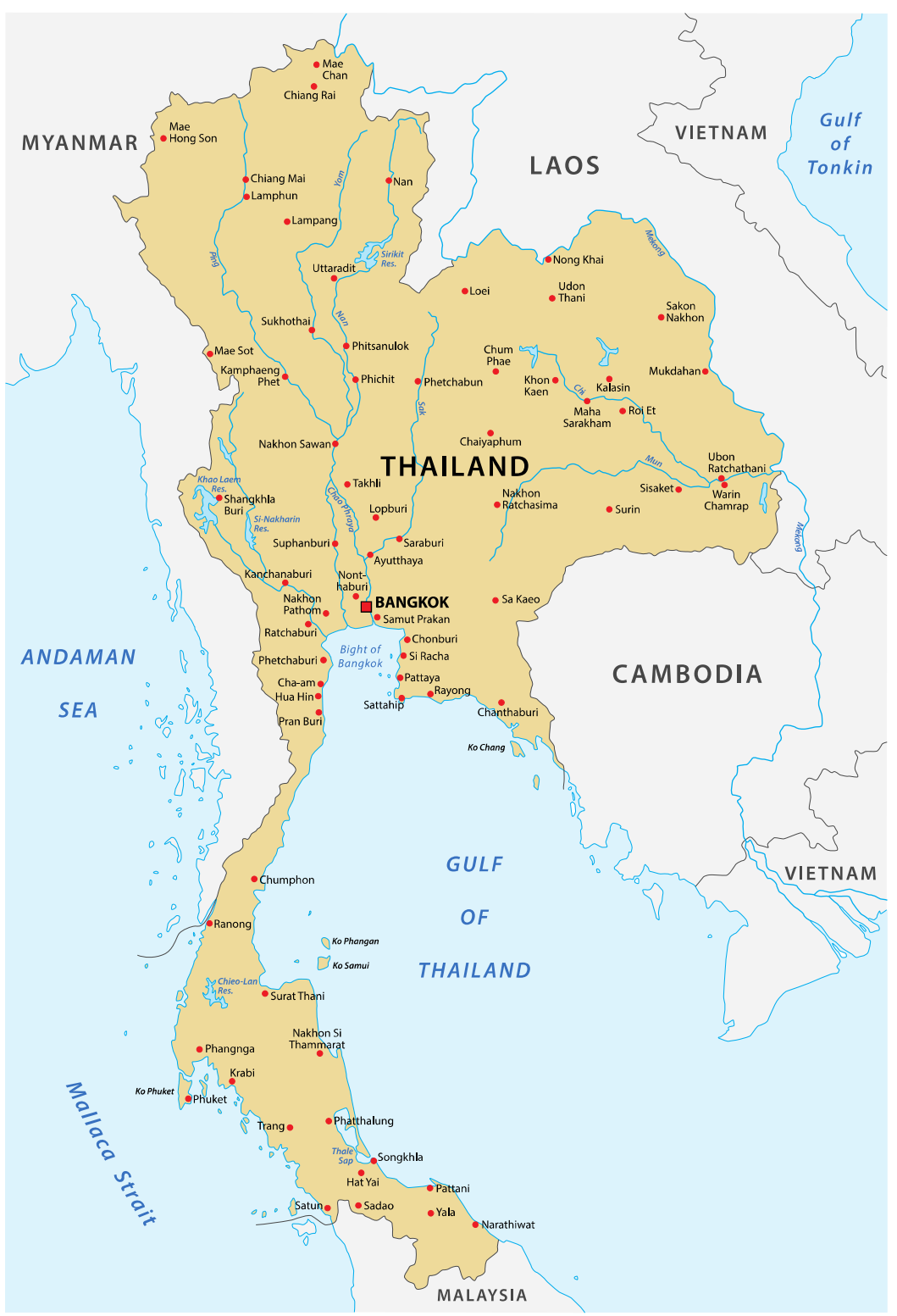

Figure 1. Map of the Thailand-Myanmar border region, circle indicates Mae Sot where data were collected. 


\subsection{Protracted Refugee Situation in Mae Sot, Thailand}

The first major wave of migrants fled to Thailand from south-eastern Myanmar in 1984, and many settled in the region around Mae Sot [2]. Since 1984, it has become a protracted refugee situation. The United Nations High Commissioner for Refugees (UNHCR) defines a protracted refugee situation as one in which 25,000 or more refugees from the same nationality have been in exile for at least five consecutive years [6]. There are approximately 140,000 UN recognized refugees living in nine Thai camps along the Thai-Myanmar border [7], yet they are only a small fraction of the total number of migrants from Myanmar living in Thailand, which is estimated to be between 1.8 million and 3 million $[8,9]$.

Myanmar continues to be affected by political instability, as a coup d'état on 1 February 2021 returned the country to full military rule [10]. As military and police enforcement intensified against paramilitary operations, a growing number of people from Myanmar fled the country to escape being arrested or otherwise suppressed, highlighting the ongoing nature of displacement in this region [11,12].

\subsection{Women's Responsibilities}

Around the world, women assume responsibilities within their families and communities. In 1993, Caroline Moser first proposed the idea that most women in low-income households have a "triple role", including reproductive, productive, and community management work [13]. Moser defined 'reproductive work' as the childbearing and rearing responsibilities and domestic tasks required to guarantee the maintenance and reproduction of the labour force, and she emphasized that it is usually unpaid [13]. Domestic tasks, such as cooking and cleaning, are undervalued responsibilities that women undertake within their homes to support the well-being of their husbands and children [14]. Moser defined 'productive work' as work done for payment in cash or kind, including both market production with an exchange value and subsistence or home production with an actual use-value but also a potential exchange value [13]. Her seminal 'triple role' theory has informed a large body of literature that draws attention to the gendered division of labour in these two spheres, particularly in low- and middle-income countries (LMICs) [15-17].

\subsection{Women's Responsibilities in Situations of Ongoing Conflict and Displacement}

During natural disasters, armed conflict, and subsequent displacement, conditions for women in LMICs often worsen $[18,19]$. Existing reproductive and productive responsibilities are exacerbated by financial insecurity and the separation of family and community members [16,20]. Ongoing conflict and displacement undermines social stability, disrupts traditional livelihoods, and erodes formal economies, so a 'coping economy' often emerges from a sheer necessity to survive, meet basic needs, and facilitate biological reproduction [21]. Women are typically forced to participate in this 'coping economy' because they are expected to care for their families during crises, when men may be engaged in armed conflict, injured, deceased, or unable to find work [21]. As displaced women enter the 'coping economy', they generally take on new responsibilities within their families, including becoming a provider, head of household, and decision maker, without any alleviation of their existing responsibilities as caretakers $[14,18]$.

Difficulties in accessing legal residency and work permits, compounded with prejudice or discrimination from host communities, may restrict migrants' mobility and prohibit them from working in the formal sector [18]. Restrictive local labour laws may lead female migrants to earn a meagre income through undesirable, dangerous, or exploitative work in the informal sector [21], which does not provide employee protection or benefits [22]. The difficulties that female migrants in situations of ongoing conflict and displacement have in finding 'suitable' work in 'feminine' sectors that does not expose them to harassment or abuse are well reported in the literature [23,24]. Fewer studies examine the challenges that female migrants face in locating work that is compatible with childcare. For example, female migrants without legal documentation may be reluctant to care for their children 
at the workplace, for fear of arrest or deportation [25], so they may pre-emptively stop working to care for their children.

Since women's new responsibilities to provide for their families have not relinquished them of their ever-present reproductive responsibilities, displaced women across the Global South have found it difficult to prioritize and meet the demands of work and childcare in new environments. Syrian refugee mothers in Turkey felt that they were trying their best to adapt but discussed the parenting challenges they faced during their busy, chore-filled days [26]. Many Syrian refugee mothers living in towns or cities in Jordan mentioned the 'multiple burdens' of balancing paid work with their reproductive responsibilities [18]. Newly displaced Syrian mothers residing in refugee camps and shelters in Syria also expressed similar feelings of being overburdened and unable to cope with daily challenges or meet their children's new needs [27]. Several Syrian women in Jordan felt that paid work outside the home was only acceptable for mothers if they could adequately care for their families and maintain their homes, since they believed unpaid reproductive responsibilities should be their priority $[18,28]$. Some of these women deeply regretted having to work because it was an unwanted distraction from caring for their children [18,28].

Existing literature has confirmed that undertaking multiple responsibilities can affect migrant mothers' daily lives and their children's overall well-being. For example, Syrian refugee mothers in Jordan frequently mentioned their worries about their children's development and behaviours as well as their guilt for not spending more time nurturing and educating their children [18]. Syrian mothers in both Jordan and Turkey reported an increase in inappropriate child behaviours and worried about how their neglect would affect their children's wellbeing over time [18,27]. Women affected by armed conflict and internal displacement in northern Uganda also conveyed their concerns that young children were becoming undisciplined [29]. These women mentioned the challenges of raising children in crowded, unfamiliar environments, where children were exposed to behaviours that mothers did not approve of [29]. Ugandan mothers also explained the difficulties of setting limits for their children in these environments [29].

A large body of literature reports on the experiences of female refugees and internally displaced persons (IDPs), yet few studies specifically focus on the experiences of women living in protracted refugee situations. Furthermore, much of the literature on international migration analyzes the experiences of refugees, asylum seekers, or migrants who are residing in high-income countries (HICs), even though the majority of forcibly displaced people resettle in neighbouring LMICs and only an estimated sixteen percent eventually resettle in HICs [30]. Considering the reproductive and productive responsibilities assumed by women in LMICs, this research sought to explore the parenting experiences of female migrants from Myanmar living in protracted refugee situations in Mae Sot, Thailand.

\section{Materials and Methods}

\subsection{Overall Study Design and Participants}

This research is part of a larger international research capacity development program and comparative study on the experiences of parenting in adversity. The broader study involved the collection of data from parents in the Eastern Democratic Republic of Congo, Mongolia, Kingston, Ontario, Canada and two regions in Thailand. Researchers from Queen's University, Canada collaborated with local practitioners and academics in each of the study locations to develop the study tools, establish a recruitment plan, train local research assistants, and undertake data collection. This specific project involved the secondary analysis of stories provided by female migrants residing in the Thai-Myanmar border region around the town of Mae Sot, Thailand. Data were collected from March to July 2019. Migrant parents living in Mae Sot were invited and selected to participate in the study. A parent was defined as someone who, at the time of the survey, was living with a child and contributing to the child rearing, or a person who had lived with a child and raised them in the past. In total, 371 self-interpreted stories, or 'micro-narratives', were 
collected among a convenience sample of self-identified migrant parents in Mae Sot by locally trained research assistants.

\subsection{Data Collection}

Data were collected by the locally trained research assistants using SenseMaker ${ }^{\circledR}$, a mixed-methods, digital data-collection application on a handheld tablet. Research assistants were chosen based on their lived experiences with migrants in the Thai-Myanmar border region and knowledge of local languages. SenseMaker ${ }^{\circledR}$ has been found to be an efficient tool for collecting data in diverse settings [31,32], and it allows the collection of perspectives on sensitive topics [31]. Brief stories from a large number of individuals can be collected in a relatively short period of time [32]. This narrative-based research methodology can be used without the need for internet access while in the field, thus facilitating data collection in low-resource or low-connectivity settings [31,32]. Participants who gave informed consent, were asked to share a story about experiences of parenting in response to one of three carefully crafted study prompts, outlined in Table 1. Participants chose a prompt to respond to, offered a story, and then answered follow-up multiple-choice survey questions to help contextualize details in the story and provide socio-demographic information. The shared narratives were entered electronically or audio recorded and transcribed from either Karen or Burmese to English at a later time. Each micro-narrative was translated into English and checked by a second local speaker to ensure meaning retention.

Table 1. Characteristics of the Study Sample of Migrant Children and Mothers in the Thai-Myanmar Border Region.

\begin{tabular}{ccc}
\hline Mother Characteristic & All Respondents \\
( $\mathbf{n = 6 2 )}$ & $\mathbf{( \% )}$ \\
\hline Age of mother in story (years) & 32 & \\
$19-40$ & 30 & 51.6 \\
$>40$ & $n$ & 48.4 \\
Child Characteristic & & $(\%)$ \\
\hline Age of child in story (years) & 12 & 19.4 \\
$1-5$ & 13 & 21.0 \\
$6-11$ & 17 & 27.4 \\
$12-18$ & 20 & 32.3 \\
$\geq 19$ & & 46.8 \\
Sex of child in story & 29 & 53.2 \\
Male & 33 & $(\%)$ \\
Female & $n$ & 66.1 \\
Family Characteristic & & 32.3 \\
Poorer than most in community & 41 & 1.6 \\
Has same money as most in community & 20 & \\
Wealthier than most in community & 1 & 8.1 \\
Degree of adversity faced by family in & & 22.6 \\
story & & 21.0 \\
None & 5 & 22.6 \\
Very little & 14 & 25.8 \\
Some & 13 &
\end{tabular}

$n$, number of shared stories.

\subsection{Study Sample}

All 371 stories from the Thailand-Myanmar border region were categorized using questions 4.11 (In this story, who is primarily parenting the child?), 4.1 (Who was the 
child in the story?), and 6.6 (What is the gender of the respondent?). Key survey items are outlined in Appendix A. The included micro-narratives were filtered using the 'Mother', 'My child', and 'Female' responses to these three questions. In other words, all first-person narratives shared by a female migrant, in which a mother is primarily parenting the child, were included. The sex and age of the narrator and the child in each micro-narrative were identified and categorized as well as other socio-demographic characteristics of the mother and child in each story, outlined in Table 1. An inductive approach to the qualitative analysis of this subset of the transcripts was undertaken, according to the Qualitative Analysis Guide of Leuven (QUAGOL) [33].

\subsection{Qualitative Data Analysis}

The QUAGOL method describes a comprehensive approach to support and facilitate the process of qualitative interview data analysis [33]. The QUAGOL method consists of ten stages, yet constantly moving between the various stages is an integral part of the research process [33]. Coding was completed using NVivo 12 analysis software. The transcripts of the included stories were thoroughly read several times to gain a robust understanding of each individual narrative. A brief narrative interview report was created for every story with an overview of the key storyline and a family tree for the parent and child in the story. The most important data from each story and complimentary narrative interview report were identified, and a nonhierarchical list of detailed first-order codes was created. A second researcher (CD) assessed the clarity and relevance of the first-order codes and any that were abstract or repetitive were revised. First-order codes were then grouped into broader thematic categories. Categories were entered as parent nodes in NVivo 12 and digitally linked to the associated passages. An additional level of coding was then undertaken for categories that were particularly rich. The first-order codes for the chosen categories were entered as child nodes in NVivo 12. All the passages linked to each category were reread and line-by-line coded with detailed first-order codes to further assess patterns in the thematic content. A summary of the research findings was then carefully written, which included significant quotes.

\subsection{Ethics}

The data were collected as part of the Parenting in Adversity: An International Comparative Study, which was granted ethical approval through the Health Sciences and Affiliated Teaching Hospitals Research Ethics Board (HSREB) at Queen's University as well as the Health Sciences Ethics Board at Mae Fah Luang University and the Community Ethics Advisory Board (CEAB) at the Mae Tao Clinic in Mae Sot, Thailand.

\section{Results}

\subsection{Demographic Characteristics}

Screening resulted in 62 first-person narratives shared by a female migrant, in which a mother is primarily parenting the child, as shown in Figure 2.

Table 1 outlines the socio-demographic characteristics of the sample. Of the participants, 64.5 percent $(n=40)$ were living alone with their children, while only 22.6 percent of the participants $(n=14)$ were living with a father or step-father, and 12.9 percent of the participants $(n=8)$ were living with a grandparent or other family member.

\subsection{Qualitative Data Analysis}

Following the QUAGOL method, 266 first-order codes (child nodes) were grouped into 29 nonhierarchical categories (parent nodes). Line-by-line coding was undertaken for eleven categories with rich content. These eleven categories were connected to two broader themes: reproductive responsibilities and productive responsibilities, as illustrated in Figure 3. 


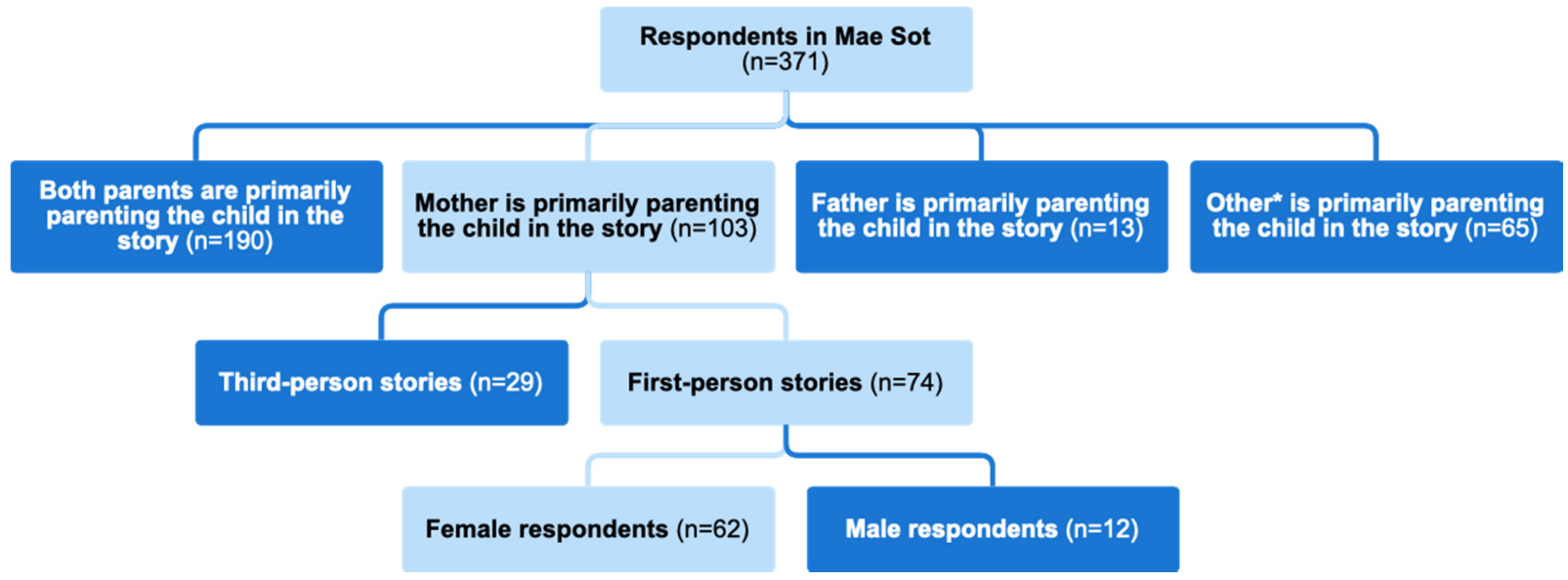

Figure 2. Flow chart depicting the subsets of micro-narratives from the international comparative study that were analyzed. * 'Other' encompasses step-mother, step-father, sister(s), brother(s), maternal grandparents, paternal grandparents, other family member, other nonfamily member, and foster or adoptive parent. All participants were self-identified migrants.
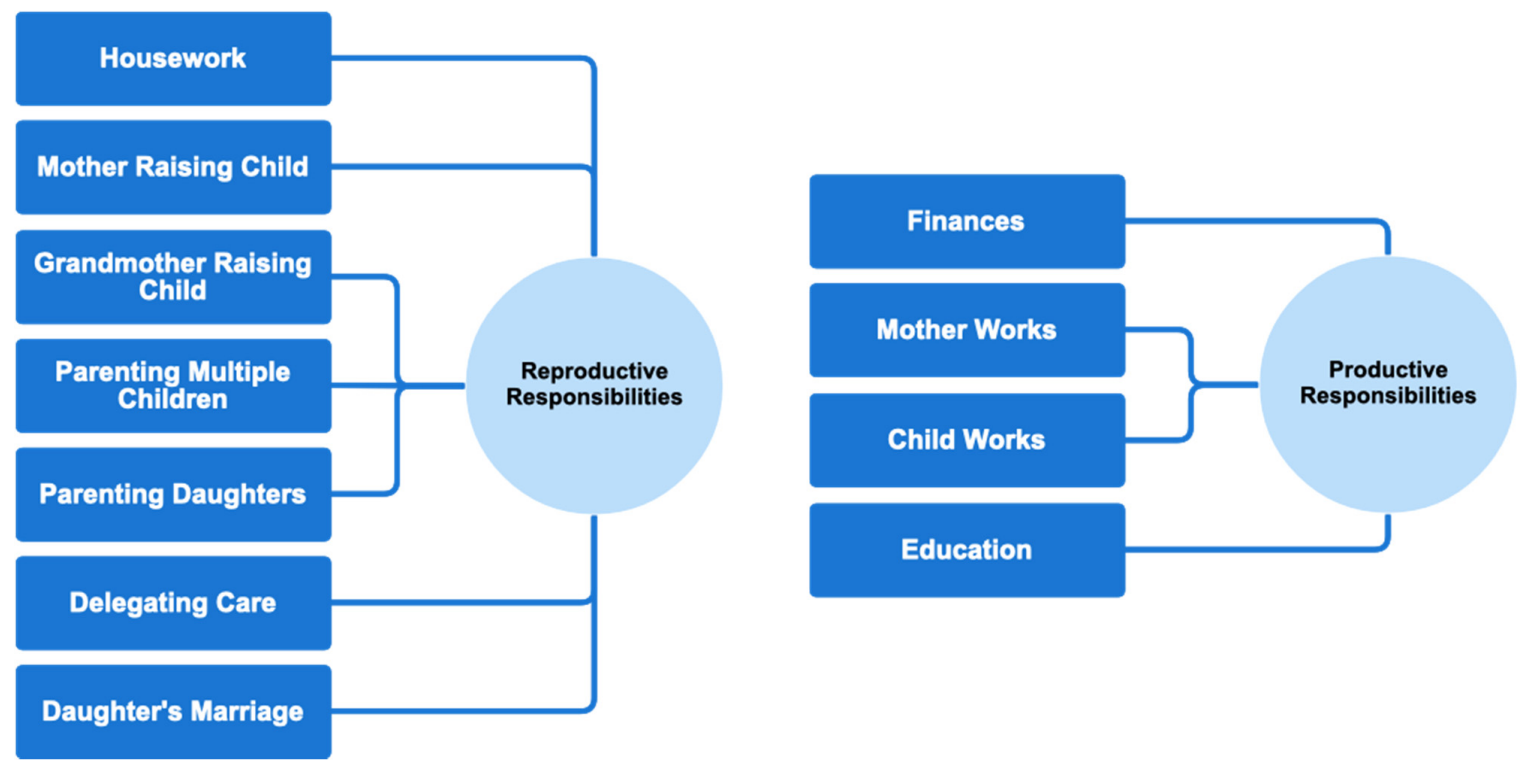

Figure 3. Conceptual framework relating the eleven parent nodes that were chosen for an additional level of coding to two broader themes. Parent nodes are depicted in dark blue rectangles, and broader themes are depicted in light blue circles.

\subsection{Reproductive and Productive Responsibilities of Female Migrants}

Female migrants' experiences in the Thai-Myanmar border region were largely shaped by the significant reproductive and productive responsibilities that they had or undertook. The most frequent reproductive responsibilities shared by migrant mothers were giving birth, breastfeeding, child rearing, educating children, and housework. Migrant mothers reported working a variety of jobs in the agricultural sector, in factories, and as roadside vendors and maids in the informal sector. Several mothers explained how they were the sole income provider for their family, so they had to work to meet their family's basic needs, such as food for their children, without financial support from their husbands or family members:

"I have to work hard to feed my children. I have four kids with him and only me had to work..."

(mother, aged 40 or older, NarrID 442)

"... I had no husband who would pay for my debt. ... Even though I could ask [for] help from my brothers, I didn't want to rely on them." 
(mother, aged 40 or older, NarrID 608)

Most migrant mothers were also the primary caregiver for their children. Since many of these mothers worked outside their homes, mothers' reproductive and productive responsibilities often overlapped, and they were forced to make difficult decisions about how to spend their time. One mother explained this struggle:

“... sometimes I think should I just stay at home and be with my children or should I just leave them and go to work. How do I look [for] money ... ? ... Only when I have work that my family ... [will] be ok."

(mother, aged 19 to 40, NarrID 652)

In order to fulfil their responsibilities to care and provide for their families, female migrants in the Thai-Myanmar border region utilized four childcare strategies: caring for children while working, caring for children instead of working, dispersing responsibilities amongst extended family members and children, and delegating reproductive responsibilities to formal and non-familial caretakers, as depicted in Figure 4.

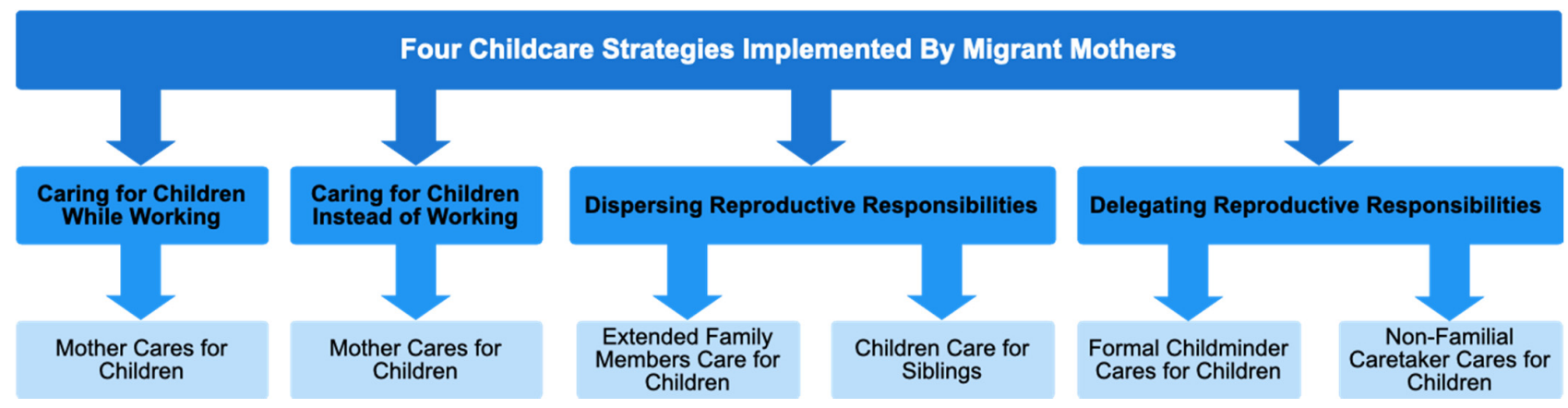

Figure 4. Conceptual framework of childcare strategies implemented by migrant mothers in the Thai-Myanmar border region.

\subsection{Strategy 1. Caring for Children While Working}

In some situations, mothers brought their children to the workplace so they could care for their children and work at the same time, compounding their reproductive and productive responsibilities:

"If my husband is not around, I work and babysit him so it is more difficult... I am working and if the child cries, I have to carry him and work."

(mother, aged 40 or older, NarrID 419)

"Since I was an artist, I performed video acting and singing when my baby was two months ... old. Therefore, I sometimes had to leave my baby with my mother. At that time, the baby did not know how to drink bottle milk, so my mother followed ... me at the shooting place and I did both acting and breast feeding during my shooting time."

(mother, aged 19 to 40, NarrID 807)

\subsection{Strategy 2. Caring for Children Instead of Working}

In other situations, mothers' reproductive and productive responsibilities conflicted, and they had to choose between raising their children and working. A few mothers reported reducing working hours to take care of their children or organizing work around childcare:

"When he was over a year, I returned to my work... My workplace is not too far from the house so I would come back home at lunch time and breastfeed him."

(mother, aged 19 to 40, NarrID 686)

However, many mothers stopped working, either temporarily or permanently, to care for their children, since reproductive responsibilities were usually more pressing than productive ones: 
"I tried working as a maid in one house, but I had to quit because of my small baby. Just like that, I couldn't work because of the kids. Since there is no one to take care of the children at home, I cannot go out for work."

(mother, aged 19 to 40, NarrID 615)

"The kid cries too much, if I don't pick him up he would be sad so most of the time I have to put aside my works. I think I will work again at the garment factory when he turns one year. Now he is too young, and I have to do the house works too."

(mother, aged 40 or older, NarrID 419)

\subsection{Strategy 3. Dispersing Responsibilities}

A few migrant mothers relied on support from extended family members to ease their reproductive responsibilities:

"Even her aunts came and help us taking care of her back then. Since I had to stay up all night feeding her, the aunts helped me in day time taking care of her."

(mother, aged 40 or older, NarrID 614)

"... it was not so difficult for me to raise him up as my parents and relatives live near us and help us.... It is much easier for us when we stay close to our parents."

(mother, aged 40 or older, NarrID 644)

"We have big family, and all family members could work and support ... her when she was schooled. ... We want her to be educated, so we all supported her and guided her."

(mother, aged 40 or older, NarrID 304)

Migrant mothers also relied on their children to share their responsibilities. Children in the Thai-Myanmar border region undertook reproductive responsibilities, such as housework, caring for their siblings, and educating their siblings:

"I tell them ... "When mother goes to work, older sons should look after the younger brothers. Take care of them well. Don't bully the younger ones. Don't do bad things." ... I tell them ... "Your younger brothers are still illiterate so teach them what you know." He then teaches his brothers. My sons ... said they will do what mother says.... So now if I say "Clean the house", they clean the house. They also prepare for cooking. ... They said if mother goes out and work, they will help with the houseworks and they will also look after their younger brothers."

(mother, aged 19 to 40, NarrID 652)

Additionally, children shared productive responsibilities with their mothers by working outside their homes to earn money.

\subsection{Strategy 4. Delegating Reproductive Responsibilities}

One mother hired a formal childminder for her daughter so she could fulfil her productive responsibilities:

"Since I do not have a husband to rely on, I face difficulties. I cannot abandon my child. I only earn 180 Baht per day, and I have to give 50 Baht to babysitter, so we do not ... [have] much money."

(mother, aged 40 or older, NarrID 291)

Other female migrants occasionally delegated reproductive responsibilities, including supervising and raising their children, to non-familial caretakers in the Thai-Myanmar border region, such as neighbours or friends.

"My husband and I were working ... so we often have to travel and leave our children with others. Step by step they would grow up with other people ... we didn't have much time to spend with them closely. Most of the time we would be away travelling and leave them with others." 
(mother, aged 19 to 40, NarrID 748)

"When my children were in Burma, I talked to the neighbour to watch them for me while I am away. ... Leaving them at first was not easy, but later on we are used to it as they grow up."

(mother, aged 19 to 40, NarrID 277)

\subsection{Challenges Associated with Living in the Thai-Myanmar Border Region}

Female migrants in the Thai-Myanmar border region reported challenges related to living in protracted refugee situations, including ongoing instability, difficulties in securing adequate, nonexploitative paid labour, and poverty.

Several migrant mothers perceived potential dangers associated with living along the Thai-Myanmar border:

"We are also at the border, there are many different kinds of people so when we hear things happening, we worry for our children. Sometimes I get worried and think if things are okay with my children when they go to school or come back home from school."

(mother, aged 40 or older, NarrID 661)

"There are both good and bad people in our environment... The community we live in was not good..."

(mother, aged 19 to 40, NarrID 629)

One mother explained how she struggled to establish relationships with her new neighbours in Mae Sot:

"When we first came to live ... [in Mae Sot] we have to live beside the river. We suffered a lot because we did not know anyone.... When we first came to live here very few people know us and they have doubt about us whether we are good or bad people. It is because of we are new to this place and were from Myanmar."

(mother, aged 40 or older, NarrID 675)

Language barriers might have been another reason why female migrants had difficulties integrating into the Mae Sot community:

"... we are Burmese migrant and could not speak Thai language very well."

(mother, aged 40 or older, NarrID 100)

\section{Discussion}

The parenting experiences of female migrants living in the Thailand-Myanmar border region are shaped by the reproductive and productive responsibilities that mothers undertake and the childcare arrangement strategies they implement to prioritize certain responsibilities or distribute their responsibilities amongst familial (family members), formal (paid childminders), and non-familial (unpaid neighbours or friends) caretakers. In situations of migration-related adversity, new responsibilities, such as earning an income in a new setting, are typically added to migrant women's existing responsibilities, including child-rearing and managing families. Since migrant mothers in the Thai-Myanmar border region frequently leave their homes to work, many struggle to navigate new, overlapping, or excessive responsibilities. This finding is consistent with other research that has been conducted in the Thailand-Myanmar border region. Oo and Kusakabe found that internally displaced Karen mothers in Myanmar discussed the challenge of balancing the demands of being both primary caretakers and providers [34]. Besides their traditional household and child-rearing tasks, these displaced mothers have taken on new and unaccustomed responsibilities, such as becoming heads of their households and earning income for their families by engaging in daily wage work [34]. Similarly, Kusakabe and Pearson reported that Burmese migrant women working in Thailand conveyed the difficulties they face in ensuring their children's well-being, while they strive to continue working, often under very exploitative conditions [25]. 
To manage their overlapping responsibilities, migrant mothers in the ThailandMyanmar border region adopted several childcare arrangement strategies. Wall and Jose, through their study on African-origin immigrants in France and Portugal, Chinese immigrants in Finland, and Moroccan immigrants in Italy, identified five childcare strategies employed by mothers: mother-centeredness (mothers cutting working hours); the superimposition of care upon work (bringing children to work); child negligence; extensive delegation of care (formal or non-familial care); and negotiation of care within the nuclear family (partners or older siblings sharing the care responsibilities) [35]. Although Wall and Jose's study was conducted amongst migrants in high-income countries, very similar childcare strategies are evident in the analyzed stories shared by migrant mothers in the Thailand-Myanmar border region. However, childcare decisions may be complicated by the challenges associated with living in protracted refugee situations. Restrictive local labour laws, potential language barriers, cultural differences, and possible prejudice or discrimination can limit the types of work that migrant mothers are able to undertake $[18,21]$ and subsequently restrict their options for childcare, rendering certain childcare arrangement strategies more prevalent than others [25].

'Mother-centeredness' and 'the superimposition of care upon work' were the most prevalent childcare strategies within the subset of analyzed stories shared by migrant mothers in Mae Sot. It is well documented that there are many gendered aspects to all forms of care giving and a large proportion of care undertaken in families and communities is done by women [36]. In several analyzed stories, mothers reported reducing working hours to take care of children or organizing work around childcare. One mother had to quit working as a maid altogether, since her children were young and no one else was available to care for them. Another mother left work at lunch time to go home and breastfeed her son. In other stories, mothers explained how they cared for their children at the workplace. Factories in Mae Sot are relatively more flexible than those in Bangkok, and employers frequently allow workers to bring their babies and children to work, so it is easier to manage childcare without the help of others [25]. In Kusakabe and Pearson's study of female Burmese migrant factory workers, 'childcare by oneself in Thailand' was a popular childcare arrangement pattern, which refers to situations where migrant mothers give birth in Thailand and take on the care of the baby themselves, even while at work [25].

Wall and Jose's 'extensive delegation of care' strategy can be accomplished with either formal or non-familial caretakers [35], yet neither of these options were particularly prevalent in the analyzed stories from the Thailand-Myanmar border region. Only nine percent of the Burmese migrant mothers that Kusakabe and Pearson interviewed had ever hired Thai women to look after their children in Mae Sot because they found formal, paid Thai childminders unsatisfactory and expensive [25]. In the analyzed stories, only one mother hired a babysitter, but she complained that she only made 180 Baht (CAD 7.17) per day and had to pay the babysitter 50 Baht (CAD 2.00). Formal childcare was likely uncommon in the Thailand-Myanmar border region because it was not affordable, mothers could not locate satisfactory childminders, or mothers preferred to leave their children under the supervision of grandparents or extended family members. Moreover, only a handful of the analyzed stories shared by migrant mothers in the Thai-Myanmar border region highlighted how neighbours helped supervise, raise, and discipline children. Kusakabe and Pearson found that the large and concentrated population of Burmese migrants in Mae Sot, likely due to the perceived ease of entry from Myanmar to this part of Thailand, created an ideal environment for the development of systems of mutual aid and community support [25]. Despite the fact that Mae Sot has a large community of Burmese migrants and so female migrants that give birth in Mae Sot may be able to rely on the support of other Burmese women in their communities [25], this childcare arrangement strategy was either not implemented by many migrant mothers in the Thai-Myanmar border region, or not shared in their micro-narratives. Non-familial care may have been uncommon in Mae Sot if migrant mothers were hesitant to depend on neighbours to care for their children, especially if they perceived dangers associated with living in the 
Thai-Myanmar border region. Language barriers and cultural differences might have been another reason why female migrants had difficulties integrating into the Mae Sot community, establishing relationships with their new neighbours, and depending on others to undertake reproductive responsibilities.

Wall and Jose's final care strategy, 'negotiation of care within the nuclear family', is further divided into three childcare arrangement patterns, which involve extended family members, and in Kusakabe and Pearson's study of Burmese migrant factory workers they described: childcare by oneself in Thailand then send child to Burma, childcare by oneself in Thailand then invite parents to come to Thailand, and childcare in Burma. Extended family members, such as grandmothers, can imbue children with intergenerational knowledge, yet they may feel obligated to help shoulder migrant mothers' responsibilities because of the nature of kinship structures and their positions within family-based networks [22]. First, 'childcare by oneself in Thailand then send child to Burma', refers to female migrants who give birth in Thailand and then send their children to Myanmar to be taken care of by relatives, while mothers continue to work in Thailand [25]. Second, 'childcare by oneself in Thailand then invite parents to come to Thailand', refers to female migrant workers who deliver in Thailand and then arrange for their parents to come to Thailand to look after the child [25]. This childcare arrangement pattern was the most popular arrangement in Mae Sot, employed by forty-six percent of mothers [25]. This care strategy was possible in Mae Sot, though very difficult to arrange in Bangkok because migrants were subject to high levels of state surveillance and control in the city [25]. Third, 'childcare in Burma', refers to the practice of delivering in Myanmar and then leaving children in the care of their grandparents and other relatives, while mothers return to work in Thailand [25]. In the analyzed stories from the Thailand-Myanmar border region, grandmothers and older female relatives frequently assumed reproductive responsibilities when mothers moved from Myanmar to Mae Sot to find work. Conversely, in Somalia, it is most often young, single female refugees who undertake reproductive responsibilities within a family, allowing their mothers, older sisters, aunts, or grandmothers to relocate elsewhere and work [22].

In situations of ongoing displacement, childcare decisions are further complicated by state regulations and surveillance [25]. Burmese migrant mothers in Mae Sot were able to employ a wider variety of childcare arrangements in Kusakabe and Pearson's study than mothers in Three Pagoda Pass or Bangkok [25]. Female migrant workers in Mae Sot were able to rely heavily on support from their families because of their close proximity to the border, potentially making it easier to travel between their home villages in Myanmar and Mae Sot without fear of arrest en route [25]. Conversely, it is difficult for unemployed extended family members to travel to Bangkok to provide childcare due to checks en route and the prohibitively high cost of living in the city [25]. Kusakabe and Pearson found that most female garment factory workers in Mae Sot who gave birth in Thailand were able to travel fairly freely to their home villages in Myanmar and were able to choose between having their children brought up by their families in Myanmar or keeping their children with them in Mae Sot [25]. It may be easier for family members to come from Myanmar to assist with childcare because staying without registration in Mae Sot may be potentially less problematic than in Bangkok [25]. Consequently, it is common to find children shifted between Mae Sot and their mother's village of origin in Myanmar [25].

\subsection{Strengths and Limitations}

This research explored the parenting experiences of female migrants from Myanmar living in protracted refugee situations in Mae Sot, Thailand, which is a unique population and setting. Only first-person narratives shared by self-identified women were analyzed to appreciate the lived experiences of potentially vulnerable and marginalized groups, which have historically been excluded from research. Analysis was undertaken according to the Qualitative Analysis Guide of Leuven (QUAGOL), which is a very structured and rigorous ten stage method for guiding analysis. A narrative interview report was created 
for every story, allowing the researcher to gain a deep and comprehensive understanding of each individual story and the entire sample. Data were collected by locally trained research assistants who were chosen based on their lived experiences with migrants in the Thailand-Myanmar border region and knowledge of local languages.

Convenience sampling was utilized to collect data from parents living along the Thailand-Myanmar border, so analyzed stories were not representative of any specific population and the results are not necessarily generalizable to other migrant populations. Furthermore, data collection was based on self-reports with local research assistants, which could have created social-desirability bias. Since the QUAGOL method is typically used to analyze longer interviews rather than micro-narratives, the narrative interview reports were generally shorter or less detailed than those for other qualitative analyses using this method.

\subsection{Implications for Future Research}

Research on how the combination of migrant mothers' reproductive and productive responsibilities can affect their children's development and overall well-being should be undertaken to develop a more comprehensive understanding of the long-term effects of different childcare arrangement strategies utilized by migrant mothers in protracted refugee situations. Moreover, several mothers in the Thailand-Myanmar border region reported working as roadside vendors and maids in the informal sector, yet this type of work does not provide employee protection or benefits [22] and may inform the childcare arrangement strategies that they are able to implement. Research on why migrant mothers undertake different types of paid labour, in either the formal or informal sector, should be conducted to explore if certain types of work are more conducive to childcare and how opportunities for gainful employment can be generated for female migrants living in protracted refugee situations. As situations of ongoing conflict and displacement continue around the world, these two areas of research deserve consideration. In future studies, mothers' experiences, responsibilities, and childcare strategies in multiple locations across the Global South could be compared.

\section{Conclusions}

In the Thailand-Myanmar border region, female migrants are caretakers, income earners, heads of their households, and decision makers. The stories they shared highlight the decisions they make to simultaneously care for their children and financially support their families. Female migrants' experiences in the Thai-Myanmar border region are largely shaped by their reproductive and productive responsibilities as well as the childcare strategies they utilize to prioritize their responsibilities or distribute them amongst their children, extended family members, neighbours, and formal childminders. By analyzing first-person narratives, this research emphasized the responsibilities and childcare strategies undertaken and shared directly by these migrant mothers. Female migrants in situations of ongoing conflict and displacement across the Global South face significant challenges finding desirable, well-paid work that does not expose them to abuse or exploitation and is compatible with childcare. The childcare arrangement strategies that migrant mothers are able to implement are likely informed by the types of work they undertake, so international and multilateral organizations as well as national policy makers should work towards legal frameworks that recognize and protect the basic rights of female migrants and their families and simplify avenues for migrants to obtain legal residency and work permits. Local government officials should amend restrictive local labour laws and insist on creating gainful employment opportunities for migrants. Nongovernmental organizations and supportive practitioners should collaborate with female migrants and local community members to provide targeted childcare support.

Author Contributions: Conceptualization, L.W. and C.M.D.; methodology, C.M.D., H.M.A., S.A.B., E.P. and L.W.; formal analysis, L.W. and C.M.D.; data collection, N.N.O., N.P.P.M. and S.T.; writingoriginal draft preparation, L.W.; writing—review and editing, all authors; supervision, C.M.D.; 
funding acquisition, C.M.D., H.M.A., S.A.B. and E.P. All authors have read and agreed to the published version of the manuscript.

Funding: This research was funded by a Queen Elizabeth Scholars-Advanced Scholars grant provided to C.M.D., H.M.A., S.A.B. and E.P. by Universities Canada.

Institutional Review Board Statement: The study was conducted according to the guidelines of the Declaration of Helsinki, and approved by the Health Sciences Research Ethics Board of Queen's University, the Health Sciences Ethics Review Board at Mae Fah Luang University Chiang Rai, Thailand and the Community Ethics Advisory Board at the Mae Tao Clinic, Mae Sot, Thailand.

Informed Consent Statement: Informed consent was obtained from all subjects involved in the study.

Data Availability Statement: The data presented in this study are available on request from the corresponding author. The data are not publicly available due to privacy and ethical requirements around data usage.

Acknowledgments: We acknowledge the mothers who participated in this study without whose stories this research would not have been possible. We would like to also acknowledge the organizations that partnered to undertake this work including the Mae Tao Clinic in Mae Sot, Thailand, the Health Information Systems Working Group in Mae Sot, Thailand, Mae Fah Luang University in Chiang Rai, Thailand and Queen's University in Ontario, Canada.

Conflicts of Interest: The authors declare no conflict of interest. The funders had no role in the design of the study; in the collection, analyses, or interpretation of data; in the writing of the manuscript, or in the decision to publish the results.

\section{Appendix A}

Table A1. Parenting in Adversity: An International Comparative Study-Detailed Survey Questions.

\begin{tabular}{|c|c|c|c|}
\hline Number ${ }^{1}$ & Question & & Possible Responses \\
\hline 1.1 & $\begin{array}{l}\text { Choose one of the questions and write } \\
\text { your story in the space below. }\end{array}$ & a. & $\begin{array}{l}\text { Think of an example of successful or unsuccessful child } \\
\text { rearing in this community. Describe an example for a } \\
\text { specific child. } \\
\text { Think about what makes it easier or more difficult to raise } \\
\text { a child in this community. Describe a specific parenting } \\
\text { situation that illustrates this for a particular child. } \\
\text { Think of a time of when you were proud of or disappointed } \\
\text { in your parenting or the parenting of someone you know. } \\
\text { Tell us that story as it relates to a specific child. }\end{array}$ \\
\hline
\end{tabular}

a. My child

4.1 Who was the child in the story?

b. A child in my extended family

c. A child in my community

d. A child I heard or read about

e. Prefer not to say

$\begin{array}{ll}\text { a. } & \text { None } \\ \text { b. } & \text { Very little } \\ \text { c. } & \text { Some } \\ \text { d. } & \text { A lot } \\ \text { e. } & \text { Extreme } \\ \text { f. } & \text { Not sure }\end{array}$


Table A1. Cont.

\begin{tabular}{|c|c|c|}
\hline Number ${ }^{1}$ & Question & Possible Responses \\
\hline 4.5 & $\begin{array}{l}\text { What was the age of the child in } \\
\text { the story? }\end{array}$ & $\begin{array}{ll}\text { a. } & \text { Less than a year } \\
\text { b. } & 1 \text { to } 5 \text { years } \\
\text { c. } & 6 \text { to } 11 \text { years } \\
\text { d. } & 12 \text { to } 18 \text { years } \\
\text { e. } & 19 \text { years or older } \\
\text { f. } & \text { Not sure }\end{array}$ \\
\hline 4.6 & What is the sex of the child in the story? & $\begin{array}{ll}\text { a. } & \text { Male } \\
\text { b. } & \text { Female } \\
\text { c. } & \text { Other }\end{array}$ \\
\hline 4.7 & $\begin{array}{l}\text { What is the age of the mother in } \\
\text { the story? }\end{array}$ & $\begin{array}{ll}\text { a. } & \text { Under } 18 \\
\text { b. } & 19 \text { to } 40 \text { years } \\
\text { c. } & \text { Over } 40 \text { years } \\
\text { d. } & \text { Not sure } \\
\text { e. } & \text { No mother in the story }\end{array}$ \\
\hline 4.10 & $\begin{array}{l}\text { Is the family in the story from any of the } \\
\text { following groups? }\end{array}$ & $\begin{array}{ll}\text { a. } & \text { Ethnic minority } \\
\text { b. } & \text { Indigenous } \\
\text { c. } & \text { Refugee } \\
\text { d. } & \text { Internally displaced } \\
\text { e. } & \text { Economic migrant } \\
\text { f. } & \text { Conflict-affected } \\
\text { g. } & \text { Disaster-affected } \\
\text { h. } & \text { Poverty } \\
\text { i. } & \text { Child with a disability } \\
\text { j. } & \text { Parent with a disability } \\
\text { k. } & \text { Unsure } \\
\text { l. } & \text { None of the above } \\
\text { m. } & \text { Other (please specify) }\end{array}$ \\
\hline 4.11 & $\begin{array}{l}\text { In this story, who is primarily parenting } \\
\text { the child? }\end{array}$ & $\begin{array}{ll}\text { a. } & \text { Mother } \\
\text { b. } & \text { Father } \\
\text { c. } & \text { Both parents } \\
\text { d. } & \text { Step mother } \\
\text { e. } & \text { Step father } \\
\text { f. } & \text { Sister(s) } \\
\text { g. } & \text { Brother(s) } \\
\text { h. } & \text { Maternal grandparents } \\
\text { i. } & \text { Paternal grandparents } \\
\text { j. } & \text { Other family member } \\
\text { k. } & \text { Other non-family member } \\
\text { l. } & \text { Foster or adoptive parent } \\
\text { m. } & \text { Other } \\
\text { n. } & \text { None }\end{array}$ \\
\hline
\end{tabular}


Table A1. Cont.

\begin{tabular}{|c|c|c|c|}
\hline Number ${ }^{1}$ & Question & & Possible Responses \\
\hline 4.12 & $\begin{array}{l}\text { With whom of the following does the } \\
\text { child in your story live? }\end{array}$ & $\begin{array}{l}\text { a. } \\
\text { b. } \\
\text { c. } \\
\text { d. } \\
\text { e. } \\
\text { f. } \\
\text { g. } \\
\text { h. } \\
\text { i. } \\
\text { j. } \\
\text { k. } \\
\text { l. } \\
\text { m. } \\
\text { n. }\end{array}$ & $\begin{array}{l}\text { Mother } \\
\text { Father } \\
\text { Step mother } \\
\text { Step father } \\
\text { Sister(s) } \\
\text { Brother(s) } \\
\text { Maternal grandparents } \\
\text { Paternal grandparents } \\
\text { Other family member } \\
\text { Other non-family member } \\
\text { Child lives in an orphanage } \\
\text { Foster or adoptive parent } \\
\text { Other } \\
\text { None }\end{array}$ \\
\hline 5.1 & What is your age? & $\begin{array}{l}\text { a. } \\
\text { b. } \\
\text { c. } \\
\text { d. } \\
\text { e. } \\
\text { f. } \\
\text { g. } \\
\text { h. }\end{array}$ & $\begin{array}{l}12-17 \\
18-24 \\
25-34 \\
35-44 \\
45-54 \\
55-64 \\
65 \text { and older } \\
\text { Prefer not to say }\end{array}$ \\
\hline 6.6 & What is the gender of the respondent? & $\begin{array}{l}\text { a. } \\
\text { b. } \\
\text { c. } \\
\text { d. }\end{array}$ & $\begin{array}{l}\text { Male } \\
\text { Female } \\
\text { Other } \\
\text { I do not know }\end{array}$ \\
\hline
\end{tabular}

${ }^{1}$ These questions represent a subset of the Parenting in Adversity: An International Comparative Study.

\section{References}

1. ReliefWeb. The Long Road to Recovery: Ethnic and Community-Based Health Organizations Leading the Way to Better Health in Eastern Burma-Myanmar. 2015. Available online: https:/ / reliefweb.int/report/myanmar/long-road-recovery-ethnic-andcommunity-based-health-organizations-leading-way-better (accessed on 20 October 2020).

2. The Border Consortium. Burma/Myanmar Programme. 2016. Available online: http://www.theborderconsortium.org (accessed on 12 April 2021).

3. Kramer, T. Ethnic Conflict and Lands Rights in Myanmar. Soc. Res. 2015, 82, 355-374. [CrossRef]

4. Karen Women's Organisation. Background of Karen People. 2016. Available online: https://karenwomen.org/history/ (accessed on 12 April 2021).

5. Jones, L. The Political Economy of Myanmar's Transition. J. Contemp. Asia 2014, 44, 144-170. [CrossRef]

6. Internal Displacement Monitoring Centre. Myanmar. 2020. Available online: https://www.internal-displacement.org/countries/ myanmar (accessed on 30 October 2020).

7. Weerasuriya, C.K.; Tan, S.O.; Alexakis, L.C.; Set, A.K.; Rijken, M.J.; Martyn, P.; Nosten, F.; McGready, R. Evaluation of a surgical service in the chronic phase of a refugee camp: An example from the Thai-Myanmar border. Confl. Health 2012, 6, 5. [CrossRef] [PubMed]

8. Human Rights Watch. Ad Hoc and Inadequate: Thailand's Treatment of Refugees and Asylum Seekers. 2012. Available online: https:/ / www.hrw.org/report/2012/09/12/ad-hoc-and-inadequate/thailands-treatment-refugees-and-asylum-seekers (accessed on 12 April 2021).

9. Sciortino, R.; Punpuing, S. International Migration in Thailand; International Organization for Thailand: Bangkok, Thailand, 2009.

10. Goldman, R. Myanmar's Coup and Violence, Explained. The New York Times, 1 February 2021.

11. Kishimoto, M. Myanmar's Neighbors Try to Keep out People Fleeing Junta Rule. Nikkei Asia, 25 March 2021. 
12. UN High Commissioner for Refugees. Myanmar Emergency Update (as of 01 September 2021). 2021. Available online: https:/ / reliefweb.int/report/myanmar/myanmar-emergency-update-01-september-2021 (accessed on 1 October 2021).

13. Moser, C. Gender Planning and Development: Theory, Practice and Training; Routledge: London, UK, 1993.

14. Rohwerder, B. Women and Girls in Forced and Protracted Displacement; Governance Social Development Humanitarian Conflict Applied Knowledge Services; University of Birmingham: Birmingham, UK, 2016; pp. 1-20.

15. Rajasingham-Senanayake, D. Between Tamil and Muslim: Women Mediating Multiple Identities in A New War. In Gender, Conflict and Migration; Behera, N.C., Ed.; Sage: New Delhi, India, 2006; pp. 175-204.

16. Hyndman, J. Feminism, Conflict and Disasters in Post-tsunami Sri Lanka. Gend. Technol. Dev. 2008, 12, 101-121. [CrossRef]

17. Balgah, R.A.; Amungwa, F.A.; Egwu, B.M.J. A Gender Analysis of Intra-Household Division of Labor in Cameroon Using Moser's Triple Roles Framework. Asian J. Agric. Ext. Econ. Sociol. 2019, 1-12. [CrossRef]

18. Culcasi, K. "We are women and men now": Intimate spaces and coping labour for Syrian women refugees in Jordan. Trans. Inst. Br. Geogr. 2019. [CrossRef]

19. GMookherjee, N. Muktir Gaan, the Raped Woman and Migrant Identities of the Bangladesh War. In Gender, Conflict and Migration; Behera, N.C., Ed.; Sage: New Delhi, India, 2006; pp. 72-96.

20. Amirthalingam, K.; Lakshman, R.W.D. Impact of Displacement on Women and Female-headed Households: A Mixed Method Analysis with a Microeconomic Touch. J. Refug. Stud. 2013, 26, 26-46. [CrossRef]

21. Peterson, S.V. 'New Wars' and gendered economies. Fem. Rev. 2008, 88, 7-22. [CrossRef]

22. Al-Sharmani, M. Transnational family networks in the Somali diaspora in Egypt: Women's roles and differentiated experiences. Gend. Place Cult. 2010, 17, 499-518. [CrossRef]

23. Buecher, B.; Aniyamuzaala, J.R. Women, Work \& War: Syrian Women and the Struggle to Survive Five Years of Conflict; CARE International: Amman, Jordan, 2016; pp. 1-41.

24. Krause, U. A Continuum of Violence? Linking Sexual and Gender-based Violence during Conflict, Flight, and Encampment. Refug. Surv. Q. 2015, 34, 1-19. [CrossRef]

25. Kusakabe, K.; Pearson, R. Cross-border childcare strategies of Burmese migrant workers in Thailand. Gend. Place Cult. 2013, 20, 960-978. [CrossRef]

26. El-Khani, A.; Ulph, F.; Peters, S.; Calam, R. Syria: Refugee parents' experiences and need for parenting support in camps and humanitarian settings. Vulnerable Child. Youth Stud. 2018, 13, 19-29. [CrossRef]

27. El-Khani, A.; Ulph, F.; Peters, S.; Calam, R. Syria: The challenges of parenting in refugee situations of immediate displacement. Intervention 2016, 14, 1. [CrossRef]

28. Boswall, K.; Al Akash, R. Personal perspectives of protracted displacement: An ethnographic insight into the isolation and coping mechanisms of Syrian women and girls living as urban refugees in northern Jordan. Interv. J. Ment. Health Psychosoc. Support Confl. Affect. Areas 2015, 13, 203-215. [CrossRef]

29. Corbin, J.N. Effect of Armed Conflict and Displacement on Women's Social, Cultural and Economic Roles and Responsibilities in Northern Uganda. J. Refug. Stud. 2019, 34, 830-850. [CrossRef]

30. Haque, S.; Malebranche, M. Impact of culture on refugee women's conceptualization and experience of postpartum depression in high-income countries of resettlement: A scoping review. PLoS ONE 2020, 15, e0238109. [CrossRef]

31. Bakhache, N.; Michael, S.; Roupetz, S.; Garbern, S.; Bergquist, H.; Davison, C.; Bartels, S. Implementation of a SenseMaker®research project among Syrian refugees in Lebanon. Glob. Health Action 2017, 10, 1362792. [CrossRef]

32. Bartels, S.A.; Saja, M.; Vahedi, L.; Collier, A.; Kelly, J.; Davison, C.; Scott, J.; Parmar, P.; Geara, P. SenseMaker ${ }^{\circledR}$ as a monitoring and evaluation tool to provide new insights on gender-based violence programs and services in Lebanon. Eval. Program Plan. 2019, 77, 101715. [CrossRef]

33. Dierckx De Casterlé, B.; Gastmans, C.; Bryon, E.; Denier, Y. QUAGOL: A guide for qualitative data analysis. Int. J. Nurs. Stud. 2012, 49, 360-371. [CrossRef]

34. Oo, Z.M.; Kusakabe, K. Motherhood and social network: Response strategies of internally displaced Karen women in Taungoo district. Women's Stud. Int. Forum 2010, 33, 482-491. [CrossRef]

35. Wall, K.; Jose, J.S. Managing Work and Care: A Difficult Challenge for Immigrant Families. Soc. Policy Adm. 2004, 38, 591-621. [CrossRef]

36. American Psychological Association. Gender Equality in Caregiving: The United Nations Response. In UN Report; Psychology International: Washington, DC, USA, 2021. 